Research Article

\title{
Distribution Service Competition with the Consideration of Different Consumer Behaviors
}

\author{
Rong Yu (D), Zhong Wu (D), and Shaojian Qu $(\mathbb{D}$ \\ Business School, University of Shanghai for Science and Technology, Shanghai 200093, China \\ Correspondence should be addressed to Zhong Wu; wuzhong_1968@163.com
}

Received 30 April 2021; Revised 21 May 2021; Accepted 31 May 2021; Published 9 June 2021

Academic Editor: Wei Zhang

Copyright ( 2021 Rong Yu et al. This is an open access article distributed under the Creative Commons Attribution License, which permits unrestricted use, distribution, and reproduction in any medium, provided the original work is properly cited.

\begin{abstract}
Logistics distribution plays an important role in the operation of e-commerce firms. This paper considers two logistics distribution modes with service competition: the e-commerce platform self-distribution (SDL) mode and third-party logistics (TPL) mode. By introducing consumer behavior into the model, we examine the competition between two firms with the same functionalities in the context of e-commerce. According to the real scene, we build the corresponding mathematical optimization model. Each firm needs to decide a logistics distribution mode and a corresponding price for the selected logistics mode. We first analyze the two firms chosen logistics modes and prices simultaneously and then extend it to Stackelberg game situation. We find out the optimal strategy for two firms. Finally, we propose numerical analysis to identify our models and provide a series of managerial insights.
\end{abstract}

\section{Introduction}

With the rapid development of information technology and electricity economy, the proliferations of economic globalization have created enormous e-commerce marketplaces. Numerous e-commerce platforms like JD.com and Amazon. com have emerged in recent years.

A crucial part coinciding with e-commerce operation is logistics distribution. Shu and Sun [1] considered an integrated distribution network design problem for an integrated supply chain. There are two major types of logistics distribution modes: the e-commerce platform SDL mode and TPL mode. To reduce the burden of e-commerce enterprises in a degree, those companies outsource their logistics functions to TPL providers. As indicated by Ellinger et al. [2], TPL service providers have been increasing the investments in expanding their capacities and major e-commerce players. A large number of practices have been carried out in the e-commerce logistics [3]. However, logistics outsourcing may fail to meet the customers' high level of logistics requirements. Some e-commerce platforms must establish SDL system. Lee and Whang [4] proved that many platforms choose to build their own logistics service network, because the logistics service quality, especially the last-mile service, is one of the most important factors for successful e-commerce business. Ellinger et al. [2] said that JD.com has invested heavily in creating their own logistics facilities like distribution centers. JD.com had 7 major logistics centers nationwide and operated 166 large warehouses in 44 cities by the end of 2015 .

For e-commerce firms, it is important to decide on choosing a better distribution mode and set the corresponding price strategy. We can find that the same goods on the same e-commerce platform may set different prices due to different distribution modes. Chen et al. [5] considered the pricing and inventory decision-making under an online retailer and an offline retailer with cooperative situation. For consumers, logistics service is also an important basis for their choice of e-commerce firms. For e-commerce firms, if they choose the e-commerce platform SDL mode, it means that e-commerce firms can better manage logistics services and shape their own service brands, making them one of their core competitiveness areas. But it is inevitable that they must invest a lot of money, and it is difficult to get a large logistics coverage in a short time. On the contrary, if they choose TPL, they can reduce the funds invested in logistics services and rapidly access to a wide range of logistics coverage. But the level of logistics services of TPL service 
providers is mixed, and e-commerce firms are difficult to form effective constraints and management for the hired TPL companies.

There are two important factors to consider when making pricing and logistics decisions. One concern is competition among homogeneous firms. E-commerce firms are in a constantly changing environment. To survive and develop, e-commerce firms need to cope with the price and logistics policies pressure of competitors. From game theory, the utility of the firms is not only depending on its own choices but also depending on the choice of its competitors. E-commerce firms need to consider how to adopt the right pricing and logistics strategies to make them in a favorable position in the market competition. The other concern is consumer behavior, consumers have service and price sensitivity, as well as channel preference, which could be measured by consumer utility. Consumer utility refers to the degree of satisfaction that a commodity brings to consumers. The utility function is the relationship between the utility acquired by consumers and the quantity of goods purchased. To realize the win-win situation between the customer and the logistics service vender, as well as maximize the value of the customer, Wang and Sang [6] analyzed the relationships between the TPL and supply chain members under an e-commerce environment. Choudhary et al. [7] assumed that consumers have different preferences in two distribution modes.

During the past decades, research on logistics distribution modes in the e-commerce context is increasingly important. Researchers have deep research on e-commerce logistics. E-commerce logistics can be analyzed in various ways, including a case study approach, multiple discriminate analysis, interpretive structural modeling, and an investment model [8-11]. Although there have been many studies on e-commerce logistics, there is still limited analysis that focuses on the competitive firm's pricing and logistics decisions, especially those taking potential factors into account such as consumer behavior.

To fill this gap, this paper aims to investigate the competitive e-commerce firms' pricing and logistics policies. By introducing consumer behavior into the model, we examine the competition between two firms with the same functionalities in the context of e-commerce. We first analyze the two firms chosen logistics modes and prices simultaneously and then extend it to Stackelberg game situation. E-commerce firms need to solve three problems while determining the optimal price and logistics strategy. First, how can competitive e-commerce firms make their own decisions based on the strategies of their competitors? Second, how does consumer behavior affect e-commerce firms' pricing and logistics decisions? Third, under different decision-making situations, how to establish the optimal model of e-commerce firms?

The class of literature relevant to the work in this paper falls into pricing and logistics decisions. With the development of e-commerce and the fierce competition in logistics industry, studies on the firms' pricing and logistics decisions have been increasing since the last decade. $\mathrm{Mu}$ et al. [12] developed a congestion pricing model for achieving efficient e-commerce logistics. Chen et al. [13] derived two different pricing strategies and three game theoretic models to address the reverse logistics of a green supply chain with environmentally conscious customers. These studies highlight the problem of price strategy in logistics. Chu et al. [14] investigated the logistics service innovation by TPL mode providers in China. We can find that, in the previous studies, there was little attention paid to SDL mode, and few considered the choice of the SDL mode and TPL, as well as the price strategy at the same time.

Our work is related to previous research on consumer behavior. It is obvious that consumer behavior can influence the consumer's purchase decision. Veena and Gopinath [15] revealed that the strategic customers play an important role in service providers' decisions. In this paper, we mainly consider the price and service sensitivity and their preferences for different logistics modes. There are some researches in overlapping areas but is not exhaustive on our problem. Tong et al. [16] considered the consumers' preferences on environmental in a retailer-led supply chain, to investigate the stability of the equilibrium solutions of the evolutionary game. Qu et al. [17] proposed a robust decision model in uncertain environment. Consumers exhibit altruistic environmental and "egoistic" brand preferences. These literatures mainly focus on the characteristics of consumer preferences.

Shin et al. [18] used conjoint analysis to estimated consumer preference for mobile telecommunication service, and the results indicated that consumer preferences for price and service quality are the most valuable attributes. Cai et al. [19] established the dynamic game relationship to coordinate a vendor-managed inventory supply chain with servicelevel sensitive customers, and related customer demand with retailer's service level. Zheng et al. [20] investigated the effect of customer value and power structure on retail supply chain product choice and pricing decisions. They defined the customer value with price sensitive. $\mathrm{Hu}$ and $\mathrm{Su}$ [21] developed an algorithm to study a news vendor's joint procurement and pricing under the price-sensitive stochastic demand. These literatures take consumer sensitivity as the research factor. Based on previous studies, it is found that scholars mainly consider one or two of the factors of consumer behavior, but seldom consider the sensitivity and preference of consumers together.

Another importance issue is competition among firms. In this study, we focus on price competition and Stackelberg game. Many scholars have also conducted certain research on price competition and game theory. Kogan and ElOuardighi [22] addressed quality improvement in a competitive duopoly market for partially substitutable products and derived Nash equilibrium pricing and induced learning effort dynamic policies. Hua et al. [23] examined the prices and optimal decisions of delivery lead time in centralized and decentralized dual-channel supply chain using the twostage optimization technique and Stackelberg game. Eltoukhy et al. [24] developed a Stackelberg-Nash game model and considered the price competition among maintenance providers. Qu et al. [25] studied a government's optimal subsidies for energy-efficient products in a 
market with two competing firms. They derived the subgame Nash equilibrium of the product prices and product efficiency strategies. Feng et al. [26] considered a dual-recycling reverse supply chain with price competition, where the recyclable dealer acts as a Stackelberg game leader, and the recycler acts as a follower. In this paper, we consider not only the Stackelberg game, but also the simultaneous game of two firms, which is also our innovation.

The rest of this article is summarized as follows. Section 2 describes the basic problems and related assumptions and constructs the corresponding model. In Section 3, according to the model, the optimal strategies of two enterprises under two scenarios of simultaneous decision-making and Stackelberg game are analyzed. In Section 4 , the sensitivity of the parameters is analyzed numerically to verify the effectiveness of the model. In Section 5, the main conclusions of this paper are summarized.

\section{Problem Description and Basic Assumptions}

2.1. Problem Description. Introducing consumer price and service sensitivity and preferences for different logistics modes into the model, we examine the competition between two firms with the same functionalities in the context of e-commerce. We study the pricing and logistics strategies of e-commerce firms under different game scenarios. The influence of each parameter on firms' decisions is also analyzed.

We consider two decision scenarios: one is the simultaneous decision-making scenario, and the other is the Stackelberg game scenario. Without loss of generality, we believe that, under the situation of simultaneous decisionmaking like Figures 1 and 2, two firms choose the same logistics distribution mode. Currently, there is only price competition between them. To occupy a favorable market share, each firm makes decisions according to its competitor. Under this situation, the consumer demand in the market is a linear relationship between the price of the two firms. Consider the price decisions and profits of two firms when they choose two logistics modes, respectively, in the context of simultaneous decision-making.

Under the Stackelberg game scenario, one of the two firms, as the leader, makes the price and logistics decisions first. And the other one, as the follower, makes the corresponding strategies according to the decisions of the leading firm. The two firms choose different logistics modes like Figures 3 and 4. Meanwhile, in addition to the price competition between the two firms, there is also competition in the level of logistics services. Consumers have different preferences for the two logistics distribution modes and are sensitive to the level of logistics services. In this scenario, the consumer's purchase decision depends on the consumer's utility. According to the consumer utility, we can establish the consumer demand model related to firms' pricing and logistics decisions. We first consider the situation that the leader chooses the e-commerce platform SDL mode, and the follower chooses the TPL, and then consider the situation that the leader chooses the TPL, and the follower chooses the e-commerce platform SDL mode. Analyze and compare the

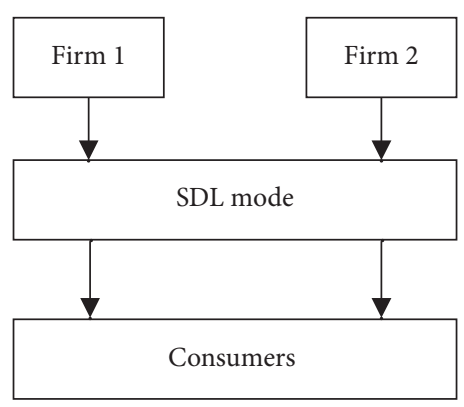

Figure 1: Logistics mode with SDL.

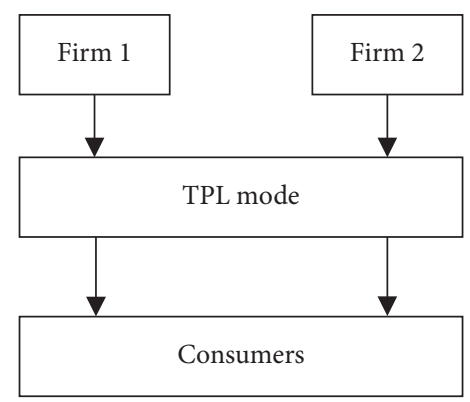

FIgURe 2: Logistics mode with TPL.

price strategies and profits of the two firms in the two cases. The notations used in this paper are listed in Table 1.

2.2. Basic Assumptions. Combined with the feasibility analysis of the modeling of real-world scene, the following basic assumptions are proposed in this paper.

(i) We assume an e-commerce firm who delivers to consumers through the e-commerce platform SDL mode or TPL mode.

(ii) We assume that consumers are rational persons, and consumer behavior can be expressed as price and service sensitivity and preference for different logistics modes. Consumers' preference for two modes of logistics is different, in which customers' acceptance of TPL is less than SDL, because the service level provided by SDL is often better than that of TPL, and consumers tend to accept SDL. They would choose the logistics mode based on the utility that consumers get. When consumer utility is greater than zero, consumers prefer the logistics mode, which makes them more efficient.

(iii) We assume that logistics service level can be expressed by delivery time. The delivery time of the two modes is different; that is, the level of logistics service is different. We assume that the service level of SDL is higher than that of TPL, $T_{s}<T_{t}$.

\section{Basic Model}

Assume that there are two firms with the same functionalities, indexed 1 and 2, competing on price and logistics distribution model decisions in the context of e-commerce. 


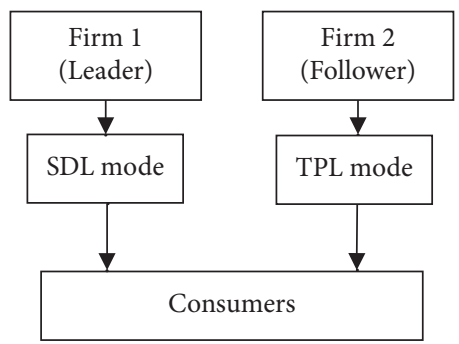

FIgURE 3: Logistics mode followers use TPL.

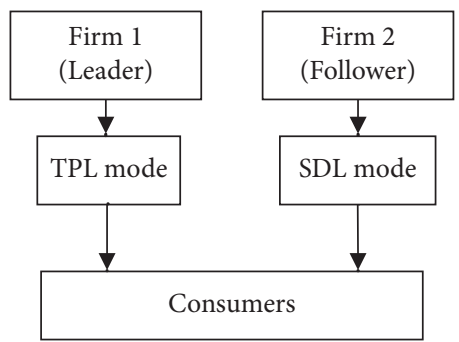

FIgURE 4: Logistics mode leaders use TPL.

TABle 1: Notations for the model.

\begin{tabular}{lc}
\hline Symbol & Descriptions \\
\hline$\alpha$ & Consumers' price sensitivity \\
$\beta$ & Consumers' service sensitivity \\
$\theta$ & The customers' acceptance of TPL \\
$\mathrm{N}$ & Consumer valuation \\
$W$ & Cost price shall be paid to the TPL supplier \\
$\mathrm{H}$ & Firm's demand sensitivities to its cross price \\
$p_{i}$ & A price set of firms (decision variable) \\
$T_{a}$ & Logistics service level \\
$\Pi$ & Firm's profits \\
$U_{a}$ & Consumer utility \\
$D$ & Demand of consumers \\
$d$ & Basic market demand \\
\hline
\end{tabular}

Each firm faces two major types of logistics distribution modes: the e-commerce platform SDL and TPL. A firm $i$ $(i=1,2)$ can choose either SDL or TPL and sets a corresponding price $p_{i}$. The service level of the two logistics distribution modes can be expressed as expected delivery time $T_{a}$. To facilitate the calculation, we set the marginal cost of the logistics service to zero when the firm chooses the e-commerce platform SDL mode. When choosing the TPL mode, the cost price that shall be paid to the TPL supplier is $w$. There is a continuum of consumers, who make purchase decisions from one of the two firms based on their evaluation. In this paper, we introduce strategic consumer and assume that consumers have price sensitivity $\alpha$; service sensitivity $\beta$; and acceptance of the TPL mode is $\theta \theta \in(0,1)$, and the acceptance of the e-commerce platform SDL mode is 1. The consumer's value of assessment for logistics service is $v$, and it is a uniform distribution from 0 to 1 , with the submergence of consumers in the market being 1 . At the time of requesting a service, the consumer chooses the service from the firm in a manner that maximizes his utility. The consumer's utility is $U_{s}=\theta v-\alpha p_{s i}-\beta T_{s}$ (SDL mode) and $U_{t}=v-\alpha p_{t i}-\beta T_{t}$ (TPL mode). For all consumers, when $U_{s}>0$, all consumers would consider accept SDL. The marginal consumer, whose value of assessment $v_{s}$ equals $\left(\alpha p_{s i}+\beta T_{s}\right) / \theta$, is indifferent to accepting SDL or not at all. Similarly, only when $U_{t}>0$, the consumers would accept TPL. The marginal consumer, whose value of assessment $v_{t}$ equals $\alpha p_{t i}+\beta T_{t}$, is indifferent to accepting SDL or not at all. If $U_{t} \geq U_{s}$, all consumers prefer TPL. The consumer's valuation $v_{s t}$ that equals $\alpha\left(p_{t i}-p_{s i}\right)+\beta\left(T_{t}-T_{s}\right) / 1-\theta$ is indifferent between the two ways. And if the valuation is larger than $v_{s t}$, they prefer TPL.

3.1. Price Competition with Simultaneous Choices. In this section, we analyze the situation that two enterprises choose the same logistics distribution mode. In detail, it analyzes which parameters will affect the logistics decision-making of enterprises and how to determine the price accordingly. Since both firms choose the same logistics distribution mode, each firm faces price-sensitive demand, which are assumed as

$$
\begin{aligned}
& D_{i}=d-\alpha p_{i}+\eta p_{j}, \\
& D_{j}=d-\alpha p_{j}+\eta p_{i},
\end{aligned}
$$

where $i \in\{1,2, \ldots, n\}, j=n+1-i, d$ represents the basic market demands, and $\eta$ denotes the demand sensitivities to its cross price. The demand function is widely used in previous studies. When both firms choose the e-commerce platform SDL mode, the profit function of the firm is

$$
\Pi_{s i}=p_{s i} D_{s i}=p_{s i}\left(d-\alpha p_{s i}+\eta p_{s j}\right) .
$$

We can solve the above functions to obtain the optimal decision.

Lemma 1. When both firms choose the e-commerce platform SDL mode, the optimal price is given by

$$
p_{s i}^{*}=\frac{d}{2 \alpha-\eta} ; \Pi_{s i}^{*}=\frac{\alpha d^{2}}{(2 \alpha-\eta)^{2}} \text {. }
$$

Proof. Let $\partial \Pi_{s i} / \partial p_{s i}=d-\alpha p_{s i}+\eta p_{s j}-\alpha p_{s i}=0$, so that $p_{s i}=d+\eta p_{s j} / 2 \alpha$, in the same way $p_{s j}=d+\eta p_{s i} / 2 \alpha$ set up two equations, and we can know that $p_{s i}^{*}=p_{s j}^{*}=d / 2 \alpha$ $-\eta D_{s i}=d-\alpha p_{s i}+\eta p_{s j}=\alpha d / 2 \alpha-\eta \Pi_{s i}=p_{s i} D_{i}=p_{s i}(d-$ $\left.\alpha p_{s i}+\eta p_{s j}\right)=\alpha d^{2} /(2 \alpha-\eta)^{2}$.

Lemma 1 implies that, without logistics distribution differentiation, competitive firms will set the same price, and it is mainly affected by the price-sensitive parameters of consumers. We can know that, with the increase of consumer price sensitivity, firms choose to lower their prices to attract more consumers. Besides, the firm's price is affected by its cross price, as the crossed price sensitivity increases, 
the firm must increase the price to occupy a certain market share. It is also interesting to note that only when $\alpha>\eta / 2$, firms make positive profits. Without loss of generality, we can get function (4) of the firm's profit when choosing the TPL mode:

$$
\Pi_{t i}=\left(p_{t i}-w\right) D_{t i}=\left(p_{t i}-w\right)\left(d-\alpha p_{t i}+\eta p_{t j}\right) .
$$

Lemma 2. When both firms choose the TPL mode, we can know the optimal decisions:

$$
\begin{aligned}
p_{t i}^{*} & =\frac{(2 \alpha+\eta) d+(\eta+1) \alpha w}{4 \alpha^{2}-\eta^{2}} \\
\Pi_{t i}^{*} & =\left[\frac{(2 \alpha+\eta) d+(\eta+1) \alpha w}{4 \alpha^{2}-\eta^{2}}-w\right] \cdot \frac{(2 \alpha+\eta) \alpha d+(\eta-\alpha)(\eta+1) \alpha w}{4 \alpha^{2}-\eta^{2}} .
\end{aligned}
$$

Proof. Similarly, let the first derivative of $\Pi_{t i}$ with respect to $p_{t i}$ equal zero. $\partial \Pi_{t i} / \partial p_{t i}=d-2 \alpha p_{t i}+\eta p_{t j}+\alpha w=0, p_{t i}=$ $d+\eta p_{t j}+\alpha w / 2 \alpha$ in the same way,

$$
\begin{aligned}
p_{t j}= & \frac{d+\eta p_{t i}+\alpha w}{2 \alpha} ; p_{t i}^{*}=\frac{(2 \alpha+\eta) d+(\eta+1) \alpha w}{4 \alpha^{2}-\eta^{2}}, \\
D_{t i}^{*}= & \frac{(2 \alpha+\eta) \alpha d+(\eta-\alpha)(\eta+1) \alpha w}{4 \alpha^{2}-\eta^{2}}, \\
\Pi_{t i}^{*}= & \left(p_{t i}-w\right) D_{t i}=\left[\frac{(2 \alpha+\eta) d+(\eta+1) \alpha w}{4 \alpha^{2}-\eta^{2}}-w\right] \\
& \cdot \frac{(2 \alpha+\eta) \alpha d+(\eta-\alpha)(\eta+1) \alpha w}{4 \alpha^{2}-\eta^{2}} .
\end{aligned}
$$

When both firms choose TPL, their price strategy is also affected by the cost factor. Interestingly, despite the increase in costs, the market demand also increased, which is due to the monopoly of TPL providers. Firms can get more profit by setting higher prices.

Lemma 3. We have $p_{t i}^{*}>p_{s i}^{*}$; $D_{t i}^{*}>D_{s i}^{*}$; when $\alpha<(\eta+1) / 4$, $\Pi_{t i}^{*}>\Pi_{s i}^{*}$.

Proof. We compare firms' decisions in two cases. We have $p_{t i}-p_{s i}=(\eta+1) \alpha w / 4 \alpha^{2}-\eta^{2}>0$, so $p_{t i}^{*}>p_{s i}^{*}$. The same as before, $D_{t i}-D_{s i}=(\eta-\alpha)(\eta+1) \alpha w / 4 \alpha^{2}-\eta^{2}>0$, we get

$$
\begin{aligned}
D_{t i}^{*}>D_{s i}^{*}, \Pi_{t i}-\Pi_{s i}= & \frac{\alpha d}{2 \alpha-\eta} \cdot \frac{(\eta-\alpha)(\eta+1) \alpha w}{4 \alpha^{2}-\eta^{2}} \\
& +\frac{\left[(\eta+1) \alpha-4 \alpha^{2}+\eta^{2}\right] w}{4 \alpha^{2}-\eta^{2}} \\
& \cdot \frac{(2 \alpha+\eta) \alpha d+(\eta-\alpha)(\eta+1) \alpha w}{4 \alpha^{2}-\eta^{2}} .
\end{aligned}
$$

It is obvious that $\alpha d / 2 \alpha-\eta \cdot(\eta-\alpha)(\eta+1) \alpha w / 4 \alpha^{2}-$ $\eta^{2}>0$ only when $\left[(\eta+1) \alpha-4 \alpha^{2}+\eta^{2}\right] w / 4 \alpha^{2}-\eta^{2}$. $(2 \alpha+\eta) \alpha d+(\eta-\alpha)(\eta+1) \alpha w / 4 \alpha^{2}-\eta^{2}>0, \quad \Pi_{t i}>\Pi_{s i}$. However, we can know $D_{\mathrm{ti}}=(2 \alpha+\eta) \alpha d+(\eta-\alpha)$ $(\eta+1) \alpha w / 4 \alpha^{2}-\eta^{2}>0$, so only if $\alpha<\eta+1 / 4, \Pi_{t i}>\Pi_{s i}$.

We usually believe that firms choose the e-commerce platform SDL mode that can save costs and obtain greater benefits. However, this is not the case. We can see from Lemma 3 that when firms choose the TPL mode, they set a higher price to cover the cost. And currently, consumer demand in the market is greater than that of consumers who choose the e-commerce platform SDL mode. When the price sensitivity of consumers and the crossprice sensitivity of enterprises meet a certain relationship, firms will get more benefits if they choose the TPL mode.

Corollary 1. In the case that two competitive firms choose the same logistics distribution mode, it is more advantageous for the two firms to choose the TPL mode.

Proof. Through the comparison in Lemma 3, we find that when two competitive firms choose the same logistics mode, they can get higher returns when they choose TPL than when they choose the e-commerce platform SDL mode.

3.2. Competition with Differentiated Choices. We consider Stackelberg game, when the two firms make decisions independently, and each aims to maximize their profit. The Stackelberg game decision structure is assumed as follows: one firm (the leader) decides upon its logistics distribution mode $T_{a}^{L}$ and price $p^{L}$ first; and then the other firm (the follower) chooses its logistics distribution mode $T_{a}^{F}$ and the corresponding price $p^{F}$. We assume that, in the Stackelberg game, two firms will not choose the same logistics distribution mode. There can be only one unique solution to maximize each firm's profit if the follower chooses the same logistics distribution mode. It is given in Section 3.1. If the leader chooses the e-commerce platform SDL mode, and the follower chooses the TPL mode, we can estimate the expected demand for each firm. All consumers whose valuation satisfies $U_{s}^{L}=v-\alpha p^{L}-\beta T_{s}^{L} \geq 0$ would buy from the leader. And if they valuation satisfies $U_{t}^{F}=\theta v-\alpha p^{F}-\beta T_{t}^{F} \geq 0$, they would consider buying from the follower. From the consumer's utility maximization principle, we can characterize the demand functions (8), as follows:

$$
\begin{gathered}
D_{s}^{L}=1-\frac{\alpha\left(p^{L}-p^{F}\right)+\beta\left(T_{s}^{L}-T_{t}^{F}\right)}{1-\theta}, \\
D_{t}^{F}=\frac{\alpha\left(\theta p^{L}-p^{F}\right)+\beta\left(\theta T_{s}^{L}-T_{t}^{F}\right)}{\theta(1-\theta)} .
\end{gathered}
$$

Based on the demand functions, we can establish the profit function (9) of two firms. The leader's priority is to maximize profit $\Pi_{t}^{L}$ by optimally deciding the price $p^{L}$ : 


$$
\Pi_{s}^{L}=p^{L} D_{s}^{L}=p^{L}\left[1-\frac{\alpha\left(p^{L}-p^{F}\right)+\beta\left(T_{s}^{L}-T_{t}^{F}\right)}{1-\theta}\right] .
$$

Similarly, the follower will try to maximize profit $\Pi_{s}^{F}$ by deciding the price as

$$
\Pi_{t}^{F}=\left(p^{F}-w\right) D_{t}^{F}=\left(p^{F}-w\right)\left[\frac{\alpha\left(\theta p^{L}-p^{F}\right)+\beta\left(\theta T_{s}^{L}-T_{t}^{F}\right)}{\theta(1-\theta)}\right] .
$$

We derive the equilibrium condition through backward induction.

Lemma 4. If the leader chooses the e-commerce platform SDL mode $T_{s}^{L}$ and the follower chooses the TPL mode $T_{t}^{F}$, for a given $p^{L}$, the follower would react by choosing a price $p^{F}=\theta / 2 p^{L}+\beta\left(\theta T_{s}^{L}-T_{t}^{F}\right)+\alpha w / 2 \alpha$; and the leader chooses price $p^{L}=1-\theta+\alpha p^{F}-\beta\left(T_{s}^{L}-T_{t}^{F}\right) / 2 \alpha$ to maximize his profit.

Proof. According to the demand and profit function established above, we can get $\Pi_{\mathrm{s}}^{L}=p^{L} D_{s}^{L}=p^{L}\left[1-\alpha\left(p^{L}-\right.\right.$ $\left.p^{F}\right)+\beta\left(T_{s}^{L}-T_{t}^{F}\right) / 1-\theta$ ] taking the first derivative with respect to $p^{L}$ and setting it equal to 0 ; then, $\partial \Pi_{\mathrm{s}}^{L} / \partial p^{L}=1-\theta-2 \alpha p^{L}+\alpha p^{F}-\beta\left(T_{s}^{L}-T_{t}^{F}\right) / 1-\theta=0$, and we get $p^{L}=1-\theta+\alpha p^{F}-\beta\left(T_{s}^{L}-T_{t}^{F}\right) / 2 \alpha$.

Similarly, $\Pi_{t}^{F}=\left(p^{F}-w\right) D_{t}^{F}=\left(p^{F}-w\right)\left[\alpha\left(\theta p^{L}-p^{F}\right)\right.$ $\left.+\beta\left(\theta T_{s}^{L}-T_{t}^{F}\right) / \theta(1-\theta)\right]$, taking the first derivative with respect to $p^{F}$, and then, $\partial \Pi_{t}^{F} / \partial p^{F}=0, \quad p^{F}=\theta / 2$ $p^{L}+\beta\left(\theta T_{s}^{L}-T_{t}^{F}\right)+\alpha w / 2 \alpha$.

Lemma 5. Based on Lemma 4, if the leader chooses the e-commerce platform SDL mode, and the follower chooses the TPL mode, the optimal prices are given by

$$
\begin{aligned}
p^{L *} & =\frac{2(1-\theta)+\beta\left[(\theta-2) T_{s}^{L}+T_{t}^{F}\right]+\alpha w}{(4-\theta) \alpha}, \\
p^{F *} & =\frac{\theta(1-\theta)+\beta \theta\left(T_{s}^{L}+T_{t}^{F}\right)+2\left(\alpha w-\beta T_{t}^{F}\right)}{(4-\theta) \alpha} .
\end{aligned}
$$

We can obtain the demands as

$$
\begin{aligned}
& D_{s}^{L}=\frac{2(1-\theta)+\beta\left[(\theta-2) T_{t}^{F}+T_{s}^{L}\right]+\alpha w}{(4-\theta)(1-\theta)}, \\
& D_{t}^{F}=\frac{\theta(1-\theta)+\beta\left[(\theta-2) T_{t}^{F}+\theta T_{s}^{L}\right]+(\theta-2) \alpha w}{(4-\theta)(1-\theta) \theta} .
\end{aligned}
$$

The profits are given by

$$
\begin{aligned}
& \Pi_{s}^{L *}=p^{L} D_{t}^{L}=\frac{\left[A+\beta\left((\theta-2) T_{s}^{L}+T_{t}^{F}\right)\right] \cdot\left[A+\beta\left((\theta-2) T_{t}^{F}+T_{s}^{L}\right)\right]}{B}, \\
& \Pi_{t}^{F *}=\left(p^{F}-w\right) D_{t}^{F}=\frac{\left[C+\beta\left((\theta-2) T_{t}^{F}+\theta T_{s}^{L}\right)\right]^{2}}{\theta B},
\end{aligned}
$$

where $A=2(1-\theta)+\alpha w, \quad B=(4-\theta)^{2}(1-\theta) \alpha, \quad C=$ $\theta(1-\theta)+(\theta-2) \alpha w$
Proof. By backward recursion, $p^{F}$ is substituted into $p^{L}$ :

$$
\begin{aligned}
p^{L} & =\frac{1-\theta+\alpha p^{F}-\beta\left(T_{s}^{L}-T_{t}^{F}\right)}{2 \alpha} \\
& =\frac{2(1-\theta)+\beta\left[(\theta-2) T_{s}^{L}+T_{t}^{F}\right]+\alpha w+\alpha \theta p^{L}}{4 \alpha} .
\end{aligned}
$$

So,

$$
\begin{aligned}
& p^{L}=\frac{2(1-\theta)+\beta\left[(\theta-2) T_{s}^{L}+T_{t}^{F}\right]+\alpha w}{(4-\theta) \alpha}, \\
& p^{F}=\frac{\theta(1-\theta)+\beta\left[(\theta-2) T_{t}^{F}+\theta T_{s}^{L}\right]+2 \alpha w}{(4-\theta) \alpha} .
\end{aligned}
$$

Based on the price function $D_{\mathrm{s}}^{L}=2(1-\theta)+$ $\beta\left[(\theta-2) T_{t}^{F}+T_{s}^{L}\right]+\alpha w /(4-\theta)(1-\theta)$, and, $D_{t}^{F}=\theta(1-\theta)$ $+\beta\left[(\theta-2) T_{t}^{F}+\theta T_{s}^{L}\right]+(\theta-2) \alpha w /(4-\theta)((1-\theta) \theta)$. By substituting the price function and demand function back into the profit function, two profit models of firms can be obtained.

Lemma 6. Firms' decisions are influenced by consumer behavior. (i) As consumer price sensitivity increases, the two firms choose to lower their prices. (ii) The higher the consumer's acceptance of the TPL mode, the greater the demand to the follower.

Proof. For

$$
\begin{aligned}
\frac{\partial p^{L}}{\partial \alpha} & =-\frac{2(1-\theta)+\beta\left[(\theta-2) T_{s}^{L}+T_{t}^{F}\right]}{(4-\theta) \alpha^{2}}<0, \frac{\partial p^{F}}{\partial \alpha} \\
& =-\frac{\theta(1-\theta)+\beta\left[(\theta-2) T_{t}^{F}+\theta T_{s}^{L}\right]}{(4-\theta) \alpha^{2}}<0
\end{aligned}
$$

it is obvious that as consumer price sensitivity increases, the two firms choose to lower their prices. As the consumer's acceptance of the TPL mode increases, consumers prefer to the TPL mode, and the demand to the follower is higher. The leader needs to take certain measures to ensure his own benefits.

Lemma 7. When $\beta / \alpha>w /(3-\theta) T_{t}^{F}-2 T_{s}^{L}$, we have $p^{L}>p^{F}$; $D_{s}^{L}>D_{t}^{F} ; \Pi_{s}^{L}<\Pi_{t}^{F}$.

Proof. We have $p^{L}-p^{F}=\left(\begin{array}{ll}\theta & -2\end{array}\right)(1-\theta)+\beta \quad[(\theta-3)$ $\left.T_{\mathrm{s}}^{L}+2 T_{t}^{\mathrm{F}}\right]+\alpha w /(4-\theta) \alpha$, only when $\beta\left[(\theta-3) T_{\mathrm{s}}^{L}+\right.$ $\left.2 T_{\mathrm{t}}^{\mathrm{F}}\right]+\alpha w>(2-\theta)(1-\theta)>0$, which means that $\beta / \alpha>w /$ $(3-\theta) T_{t}^{F}-2 T_{s}^{L} p^{L}>p^{F} ; D_{\mathrm{s}}^{L}-D_{t}^{F}=\theta(1-\theta)+\beta(\theta-1)(\theta-$ 2) $T_{t}^{F}+2 \alpha w /(4-\theta)(1-\theta) \theta>0$,. So, $D_{s}^{L}>D_{t}^{F}$; Clearly, $\Pi_{s}^{L}<\Pi_{t}^{F}$.

Lemma 7 has several important managerial implications. Firms need to consider consumer behavior when making their pricing and logistics decisions. When $\beta / \alpha>w /$ $\left[(3-\theta) T_{t}^{F}-2 T_{s}^{L}\right]$, to occupy more market shares and obtain higher profits, the leader chooses to set higher prices. The leaders have certain decision-making advantages, and they can take the lead in choosing favorable pricing and logistics strategies. Without loss of generality, we can characterize the 
demand functions the same as before. If the leader chooses the TPL mode, and the follower chooses the SDL mode, the consumer's utility is $U_{t}^{L}=\theta v-\alpha p^{L}-\beta T_{t}^{L}, \quad U_{s}^{F}=v-$ $\alpha p^{F}-\beta T_{s}^{F}$. The demand functions are as follows: $D_{t}^{L}=\alpha(\theta$ $\left.p^{F}-p^{L}\right)+\beta\left(\theta T_{s}^{F}-\quad T_{t}^{L}\right) / \theta(1-\theta), D_{s}^{F}=1-\alpha \quad\left(p^{F}-p^{L}\right)$ $+\beta\left(T_{s}^{F}-T_{t}^{L}\right) / 1-\theta$.

Similarly, the leader's profit is $\Pi_{t}^{L}=\left(p^{L}-w\right)$ $\alpha\left(\theta p^{F}-p^{L}\right)+\beta\left(\theta T_{s}^{F}-T_{t}^{L}\right) / \theta(1-\theta)$, and the follower's profit is $\Pi_{s}^{F}=p^{F}\left[1-\alpha\left(p^{F}-p^{L}\right)+\beta\left(T_{s}^{F}-T_{t}^{L}\right) / 1-\theta\right]$.

Lemma 8. If the leader chooses the TPL mode $T_{t}^{L}$, and the follower chooses the e-commerce platform SDL mode $T_{s}^{F}$, the leader sets his price as $p^{L}=\theta / 2 p^{F}+\beta\left(\theta T_{s}^{F}-T_{t}^{L}\right)+\alpha w / 2 \alpha$, and the follower would react by choosing a price as $p^{F}=1-\theta+\alpha p^{L}-\beta\left(T_{s}^{F}-T_{t}^{L}\right) / 2 \alpha$

Proof. Same to the Proofs above, we get $\Pi_{t}^{L}=\left(p^{L}-w\right)\left[\alpha\left(\theta p^{F}-p^{L}\right)+\beta\left(\theta T_{s}^{F}-T_{t}^{L}\right) / \theta(1-\theta)\right]$, taking the first derivative with respect to $p^{L}$ and setting it equal to 0 ; then, $\partial \Pi_{t}^{L} / \partial p^{L}=0$

$\alpha \theta p^{F}-2 \alpha p^{L}+\beta\left(\theta T_{s}^{F}-T_{t}^{L}\right)+\alpha w / \theta(1-\theta)=0, p^{L}=\theta / 2$ $p^{F}+\beta\left(\theta T_{s}^{F}-T_{t}^{L}\right)+\alpha w / 2 \alpha ; \quad$ similarly, $\quad \Pi_{s}^{F}=p^{F} D_{s}^{F}=p^{F}$ $\left[1-\alpha\left(p^{F}-p^{L}\right)+\beta\left(T_{s}^{F}-T_{t}^{L}\right) / 1-\theta\right]$, taking the first derivative with respect to $p^{F}$ and setting it equal to 0 ; then, $\partial \Pi_{s}^{F} / \partial p^{F}=1-\theta-2 \alpha p^{F}+\alpha p^{L}-\beta\left(T_{s}^{F}-T_{t}^{L}\right) / 1-\theta=0, \quad p^{F}$ $=1-\theta+\alpha p^{L}-\beta\left(T_{s}^{F}-T_{t}^{L}\right) / 2 \alpha$.

Lemma 9. If the leader chooses the TPL mode $T_{t}^{L}$, and the follower chooses the e-commerce platform SDL mode $T_{s}^{F}$, the optimal prices are given by

$$
\begin{aligned}
& p^{L *}=\frac{\theta(1-\theta)+\beta\left[(\theta-2) T_{t}^{L}+\theta T_{s}^{F}\right]+2 \alpha w}{(4-\theta) \alpha}, \\
& p^{\mathrm{F}^{*}}=\frac{2(1-\theta)+\beta\left[T_{t}^{L}+(\theta-2) T_{s}^{F}\right]+\alpha w}{(4-\theta) \alpha} .
\end{aligned}
$$

We can obtain the demands as

$$
\begin{aligned}
D_{\mathrm{t}}^{L} & =\frac{\theta(1-\theta)+\beta\left[(\theta-2) T_{t}^{L}+\theta T_{s}^{F}\right]+(\theta-2) \alpha w}{(4-\theta)(1-\theta) \theta}, \\
D_{\mathrm{s}}^{F} & =\frac{2(1-\theta)+\beta\left[(\theta-2) T_{t}^{L}+T_{s}^{F}\right]+\alpha w}{(4-\theta)(1-\theta)} .
\end{aligned}
$$

The profits are given by

$$
\begin{aligned}
\Pi_{\mathrm{t}}^{L *} & =\frac{\left[C+\beta\left((\theta-2) T_{t}^{L}+\theta T_{s}^{F}\right)\right]^{2}}{\theta B}, \\
\Pi_{\mathrm{s}}^{F *} & =\frac{\left[A+\beta\left((\theta-2) T_{s}^{F}+T_{t}^{L}\right)\right]\left[A+\beta\left((\theta-2) T_{t}^{L}+T_{s}^{F}\right)\right]}{B} .
\end{aligned}
$$

Proof. By backward recursion, $p^{L}$ is substituted into $p^{F}$,

$$
p^{F}=\frac{2(1-\theta)+\alpha \theta p^{F}+\beta\left[T_{t}^{L}+(\theta-2) T_{s}^{F}\right]+\alpha w}{4 \alpha} .
$$

So

$$
\begin{aligned}
& p^{\mathrm{F}}=\frac{2(1-\theta)+\beta\left[T_{s}^{L}+(\theta-2) T_{s}^{F}\right]+\alpha w}{(4-\theta) \alpha}, \\
& p^{L}=\frac{\theta(1-\theta)+\beta\left[(\theta-2) T_{t}^{L}+\theta T_{s}^{F}\right]+2 \alpha w}{(4-\theta) \alpha} .
\end{aligned}
$$

Based on the price function,

$$
\begin{aligned}
D_{\mathrm{t}}^{L} & =\frac{\theta(1-\theta)+\beta\left[(\theta-2) T_{t}^{L}+\theta T_{s}^{F}\right]+(\theta-2) \alpha w}{(4-\theta)(1-\theta) \theta}, \\
D_{\mathrm{s}}^{F} & =\frac{2(1-\theta)+\beta\left[(\theta-2) T_{t}^{L}+T_{s}^{F}\right]+\alpha w}{(4-\theta)(1-\theta)} .
\end{aligned}
$$

By substituting the price function and demand function back into the profit function, two profit models of firms can be obtained.

Lemma 10. When $\beta<(2-\theta)(1-\theta)-\alpha w / \quad(\theta-3)$ $T_{t}^{L}+2 T_{s}^{F}$, then, $p^{L}<p^{F} ; D_{t}^{L}<D_{s}^{F} ; D_{t}^{L}<D_{s}^{F}$.

Proof. We can know that $p^{F}-p^{L}=(2-\theta)(1-\theta)+$ $\beta\left[(3-\theta) T_{t}^{L}-2 T_{s}^{F}\right]-\alpha w$, only when $\beta<(2-\theta)(1-\theta)$ $-\alpha w /(\theta-3) T_{t}^{L}+2 T_{s}^{F}$, and we have $p^{F}-p^{L}>0, p^{F}>p^{L}$; $D_{s}^{F}-D_{t}^{L}=\theta(1-\theta)+\beta\left[(\theta-1)(\theta-2) T_{t}^{L}\right]+2 \alpha w>0$, which means $D_{s}^{F}>D_{t}^{L}$;

Clearly, $\Pi_{t}^{L}>\Pi_{s}^{F}$.

If the leader chooses the TPL mode $\left(T_{t}^{L}\right)$, and the follower chooses the e-commerce platform SDL mode $\left(T_{s}^{F}\right)$, the follower sets his pricing strategies based on the leader's strategy. Considering the behavioral factors of consumers, when the price and service sensitivity, as well as the channel 
sensitivity, satisfy a certain relationship, the follower sets a higher price than the leader according to the market conditions to obtain more profit.

Lemma 11. If $\beta>\alpha w+(\theta-2)(1-\theta) /(3-\theta) T_{t}-2 T_{s}$, $p_{s}^{L}>p_{t}^{L} ; D_{s}^{L}>D_{t}^{L} ; \Pi_{s}^{L}<\Pi_{t}^{L}$.

Proof. $p_{s}^{L}-p_{t}^{L}=(2-\theta)(1-\theta)+\beta\left[(3-\theta) T_{t}-2 T_{s}\right]-\alpha w /$ $(4-\theta) \alpha$; only when $\beta>\alpha w+(\theta-2)(1-\theta) /(3-\theta) T_{t}$ $-2 T_{s}, p_{s}^{L}-p_{t}^{L}>0, p_{s}^{L}>p_{t}^{L} ; D_{s}^{L}>D_{t}^{L}, D_{s}^{L}-D_{t}^{L}=\theta(1-\theta)+$ $\beta\left[(\theta-1)(\theta-2) T_{t}\right]+2 \alpha w /(4-\theta) \quad(1-\theta) \quad \theta>0$. Clearly, $\Pi_{s}^{L}<\Pi_{t}^{L}$.

Lemma 12. If $\beta>\alpha w+(\theta-2)(1-\theta) /(3-\theta) T_{t}-2 T_{s}$, $p_{s}^{F}>p_{t}^{F} ; D_{s}^{F}>D_{t}^{F} ; \Pi_{s}^{F}<\Pi_{t}^{F}$.

Proof.

$$
\begin{aligned}
p_{s}^{F}-p_{t}^{F} & =\frac{(2-\theta)(1-\theta)+\beta\left[(3-\theta) T_{t}-2 T_{s}\right]-\alpha w}{(4-\theta) \alpha}, \\
\beta & >\frac{\alpha w+(\theta-2)(1-\theta)}{(3-\theta) T_{t}-2 T_{s}}, \\
p_{s}^{F}-p_{t}^{F} & >0, p_{s}^{F}>p_{t}^{F}, \\
D_{s}^{F}-D_{t}^{F} & =\frac{\theta(1-\theta)+\beta\left[(\theta-1)(\theta-2) T_{t}\right]+2 \alpha w}{(4-\theta)(1-\theta) \theta}>0, \\
D_{s}^{F} & >D_{t}^{F} \\
\Pi_{s}^{F} & <\Pi_{t}^{F}
\end{aligned}
$$

From Lemmas 11 and 12, we can see that, in the Stackelberg game, we consider the consumer behavior factor, when the leader chooses the e-commerce platform SDL mode, and the follower chooses the TPL mode, which is more beneficial to the leader. When the leader chooses the TPL mode, the follower chooses the e-commerce platform SDL mode, which is more beneficial to the follower.

Corollary 2. Under the Stackelberg game scenario, we believe that competitive e-commerce firms tend to choose the TPL mode to obtain higher profits.

Proof. From Propositions 5 and 6, it is obvious that $\Pi_{s}^{L}>\Pi_{t}^{L}$; $\Pi_{s}^{F}>\Pi_{t}^{F}$. Under the Stackelberg game scenario, competitive e-commerce firms tend to choose the e-commerce platform SDL mode to obtain higher profits.

3.3. Parametric Analysis. This paper examines the pricing and logistics strategies of competitive e-commerce firms considering consumer behavior. In this section, we discuss how consumer behavioral and other factors influence the decisions of competitive firms. We assume that consumers have price sensitivity $\alpha$; service sensitivity $\beta$; and acceptance of the TPL mode is $\theta, \theta \in(0,1)$. The demand sensitivities to its cross price are $\eta$. The cost price that shall be paid to the TPL supplier is $w$. Under the two firms with simultaneous choices scenario, we believe that there is only price competition between the two firms and consider the price sensitivity of consumers.

Corollary 3. When both firms choose the e-commerce platform SDL mode, as the price sensitivity of consumers ( $\alpha$ ) increases, the profits of two firms $\left(\Pi_{s i}\right)$ will decrease. As the price competition between enterprises $(\eta)$ increases, the profits of two firms $\left(\Pi_{\text {si }}\right)$ will increase.

Proof. When both firms choose the e-commerce platform SDL mode,

$$
\frac{\partial \Pi_{s i}}{\partial \alpha}=-\frac{d^{2}(2 \alpha+\eta)}{2 \alpha-\eta}<0 ; \frac{\partial \Pi_{s i}}{\partial \eta}=\frac{2 \eta \alpha d^{2}}{(2 \alpha-\eta)^{3}}>0 .
$$

Corollary 4. When both firms choose the TPL mode, as the price sensitivity of consumers $\alpha$ increases, the profits of the two firms $\Pi_{t i}$ will decrease. As the price competition between enterprises $\eta$ increases, the profits of two firms $\Pi_{t i}$ will increase.

Proof. When both firms choose TPL mode,

$$
\frac{\partial \Pi_{t i}}{\partial \alpha}=-\frac{2 d}{(2 \alpha-\eta)^{2}}<0 ; \frac{\partial \Pi_{t i}}{\partial \eta}>0 .
$$

Under the Stackelberg game scenario, there are not only the price and service sensitivity of consumers, but also the logistics channels preferences of consumers, when the leader chooses the e-commerce platform SDL mode $T_{s}^{L}$ and the follower chooses the TPL mode $T_{t}^{F}$.

Corollary 5. As consumer price sensitivity increases, both firms will reduce their prices. For the leader, when $T_{t} / T_{s}>2-\theta$, as consumer service sensitivity $\beta$ increases, the leader will set higher prices. For the follower, when $T_{t} / T_{s}<\theta / 2-\theta$, as consumer service sensitivity $\beta$ increases, the follower will set higher prices.

Proof. We have

$$
\frac{\partial p^{L}}{\partial \beta}=\frac{(\theta-2) T_{s}^{L}+T_{t}^{F}}{(4-\theta) \alpha}, \frac{\partial p^{F}}{\partial \beta}=\frac{(\theta-2) T_{t}^{F}+\theta T_{s}^{L}}{(4-\theta) \alpha} .
$$

For the leader, when $T_{t} / T_{s}>2-\theta, \partial p^{L} / \partial \beta>0$, as consumer service sensitivity $(\beta)$ increases, the leader will set higher prices. For the follower, when $T_{t} / T_{s}<\theta / 2-\theta$, $\partial p^{F} / \partial \beta>0$ as consumer service sensitivity $(\beta)$ increases, the follower will set higher prices.

If the leader chooses the TPL mode $T_{t}^{L}$, the follower will choose the e-commerce platform SDL mode $\left(T_{s}^{F}\right)$.

Corollary 6. As consumer price sensitivity increases, both firms will reduce their prices. For the leader, when $T_{t} / T_{s}<\theta / 2-\theta$, as consumer service sensitivity $\beta$ increases, 
the leader will set higher prices. For the follower, when $T_{t} / T_{s}>2-\theta$, as consumer service sensitivity $\beta$ increases, the follower will set higher prices.

Proof. If the leader chooses the TPL mode, and the follower chooses the e-commerce platform SDL mode, we have $\partial p^{L} / \partial \beta=(\theta-2) T_{\mathrm{t}}^{L}+\theta T_{s}^{F} /(4-\theta) \alpha, \quad \partial p^{F} / \partial \beta=(\theta-2) T_{s}^{F}+$ $T_{t}^{L} /(4-\theta) \alpha$. For the leader, when $T_{t} / T_{s}<\theta / 2-\theta, \partial p^{L} / \partial \beta>0$ as consumer service sensitivity $\beta$ increases, the leader will set higher prices. For the follower, when $T_{t} / T_{s}>2-\theta$, $\partial p^{F} / \partial \beta>0$ as consumer service sensitivity $\beta$ increases, the follower will set higher prices.

\section{Numerical Analyses}

In this section, we present a numerical analysis to test the previous inference and explore some properties. To explore the pricing and logistics policies in competitive e-commerce firms, we put forward the parameters value in Section 4.1 to make a mapping analysis in Section 4.2 to illustrate the influence of parameters on $p_{i}, D_{i}, \Pi_{i}$.

4.1. Basic Parameters. In numerical analysis, we considered that there was completely competitive market, and the total market share is 1. E-commerce firms compete between the market shares by choosing pricing and logistics strategies. We consider two different competitive scenarios, one of which is the simultaneous decision scenario, and the other is the Stackelberg game scenario. Under the simultaneous decision scenario, we only consider the consumer price sensitivity factor, as well as competitive factor among e-commerce firms. Without loss of generality, we set basic market demand $d=10$; cost price shall be paid to the TPL supplier $w=5$; the consumer price sensitivity factor $\alpha \in(0,1)$; the competitive factor among e-commerce firms $\eta \in(0,1)$. Under the Stackelberg game scenario, there are not only behavioral factors of consumers, but also competition among logistics distribution modes. Consumers have price sensitivity $\alpha \in(0,1)$; service sensitivity $\beta \in(0,1)$; and acceptance of the TPL mode is $\theta, \theta \in(0,1)$. We assume that the logistics service level $T_{s}=5, T_{t}=7, \theta=0.8$.

4.2. Sensitivity Analysis. This section analyzes the influence of price sensitivity coefficient, service sensitivity coefficient and competition factors on e-commerce enterprise price strategy, consumer demand, and enterprise optimal profit under different scenarios. In the part of numerical cases, Matlab is used for numerical analysis. In the previous analysis, we can know that consumer behavior and competition between enterprises and game order have a great impact on the decision-making of e-commerce enterprises. This paper divides consumer behavior into price sensitivity, service sensitivity, and acceptance of logistics mode. We plot the relationship between sensitivity and price, consumer demand, and corporate income and further analyze their trends and impacts. In addition, this paper further discusses the impact of e-commerce enterprise's price and logistics decision-making on enterprise income under different game situations.

First, we can draw the price strategies and revenue situation of two competitive e-commerce firms when they choose different logistics distribution modes, respectively, under the simultaneous decision-making situation. After that, we discuss the influence of decision-making order of two e-commerce firms on price and logistics strategies under the situation of Stackelberg game. Finally, sensitivity analysis is conducted on each parameter to explore the influence of consumer behavior on the pricing and logistics policies of competitive e-commerce firms.

From the Figures 5(a) and 5(b), we can get the price decisions and revenue change trend of two competitive e-commerce firms under the simultaneous decision-making situation. Figures describe the price decision changes of two firms when they simultaneously choose the e-commerce platform SDL mode and TPL. To fit the situation, we consider the right half of the image. The change trend of the two images is basically the same. With the increase of consumer price sensitivity, firms choose to lower their prices to attract more consumers.

Figures 6(a) and 6(b) show the demand functions in the simultaneous decision situation. Under the simultaneous decision situation, only price competition exists among firms. Consumer demand is only affected by factors related to price. From Figure 6, we can see that the change trend of consumer demand is basically the same as Figure 5. When the price sensitivity of consumers increases, it means that consumers pay more attention to price changes, and their willingness to pay will decrease, thus affecting their demand.

Interestingly, we can find from Figures $7(\mathrm{a})$ and $7(\mathrm{~b})$ that, under the two logistics modes, the profits of the two firms show a fission trend of increasing first and then decreasing. When the price sensitivity of consumers and the cross-price sensitivity of firms are lower than a certain threshold, the income of two firms increases sharply after a gentle increase. When the parameters exceed the threshold value, the profit of the firms decreases sharply and then decreases gently. The profit functions in the middle interval have a linear relationship with the sensitivity parameters. No matter what kind of logistics mode a firm chooses, it hopes to find this threshold to maximize its benefits. Meanwhile, all other parameters remain the same, and as the price sensitivity of consumers increases, the profits of two firms will decrease; as the price competition between enterprises increases, the profits of two firms will increase.

Similarly, Figures 8(a) and 8(b) show the price strategies and profits comparison. As the crossed price sensitivity increases, namely, the competition intensity between two firms increases, firms choose to increase their prices to ensure their competitive advantages and occupy the dominant position in the market. In Figure 8(a), we further compare the price strategies of different logistics modes. Obviously, when the two firms choose the TPL mode, the price set by them is higher than that of the e-commerce platform SDL mode, which is due to the need of outsourcing costs. We also compare the two profit functions in 


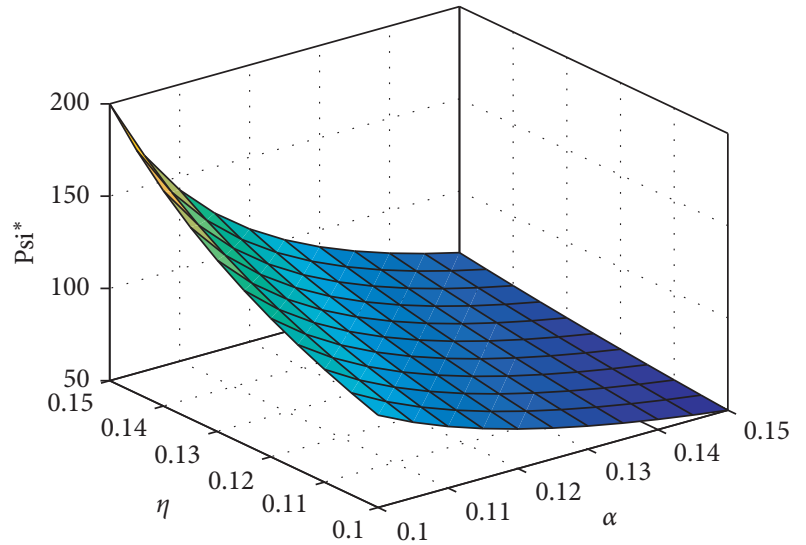

(a)

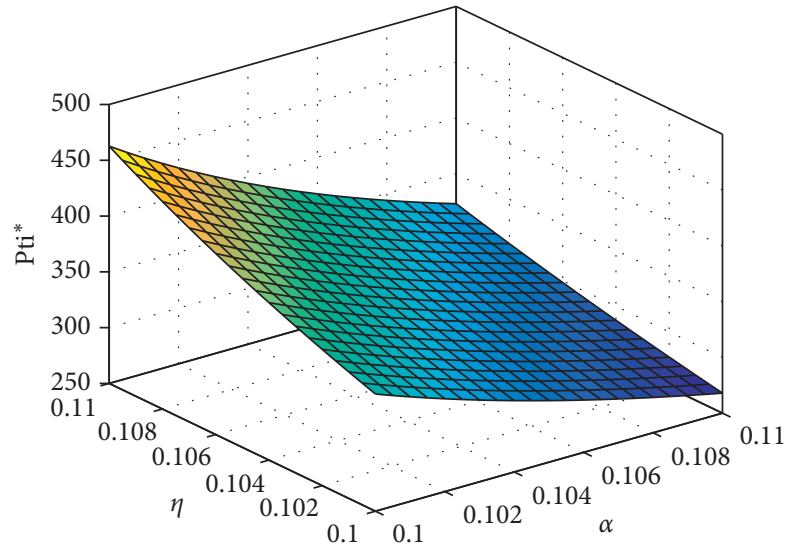

(b)

Figure 5: Price strategies in the simultaneous decision situation. (a) $p_{s i}^{*}$ (b) $p_{t i}^{*}$.

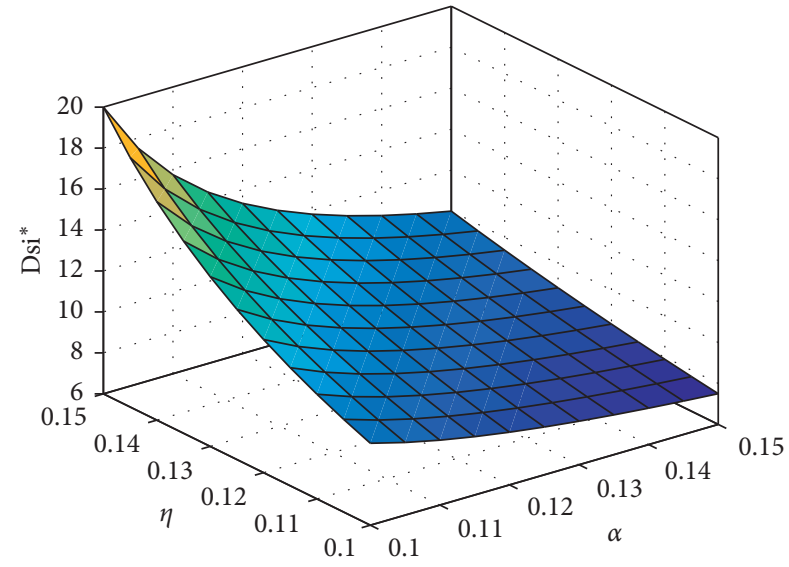

(a)

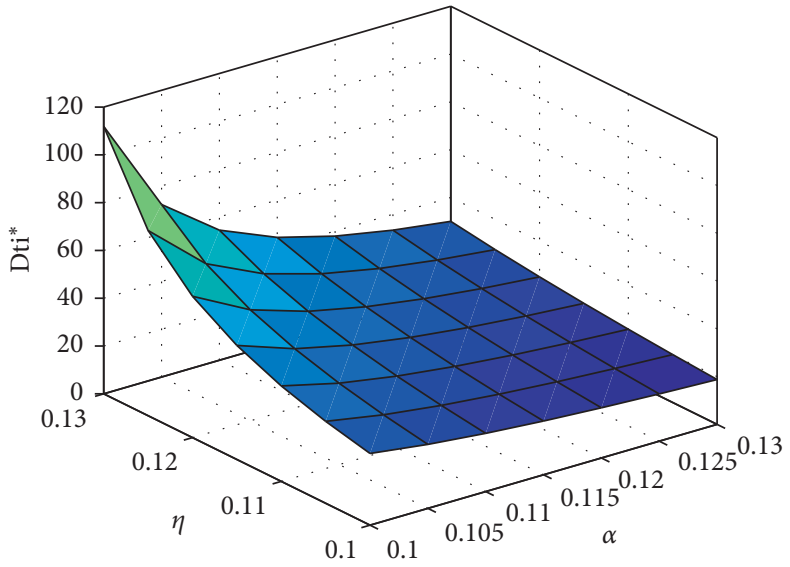

(b)

Figure 6: Demand functions in the simultaneous decision situation. (a) $D_{s i}^{*}$ (b) $D_{t i}^{*}$.

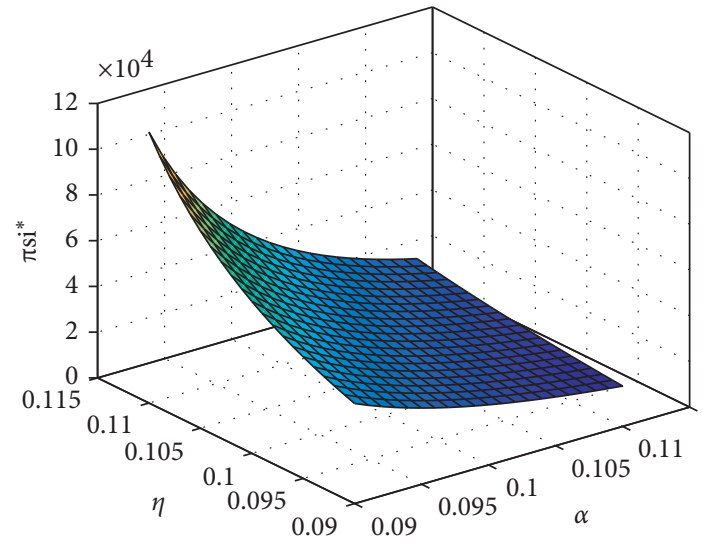

(a)

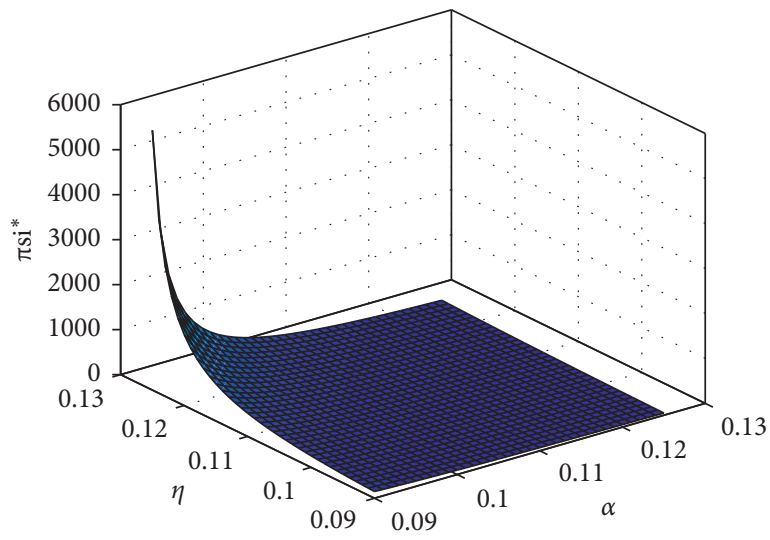

(b)

Figure 7: Profits in the simultaneous decision situation. (a) $\Pi_{s i}$ (b) $\Pi_{t i}$.

Figure 8(b). It can be seen that the revenue of choosing thirdparty logistics before functional fission is higher than that of choosing independent distribution model of e-commerce platform. After the fission, the profit of choosing the TPL is in the absolute advantage at the beginning and then lower than that of the SDL. In general, it is more advantageous for firms to choose TPL rather than SDL.

Figures 9(a) and 9(b) show the price strategies under the Stackelberg game. We discuss the decision-making of e-commerce firms in the context of the Stackelberg game. In 


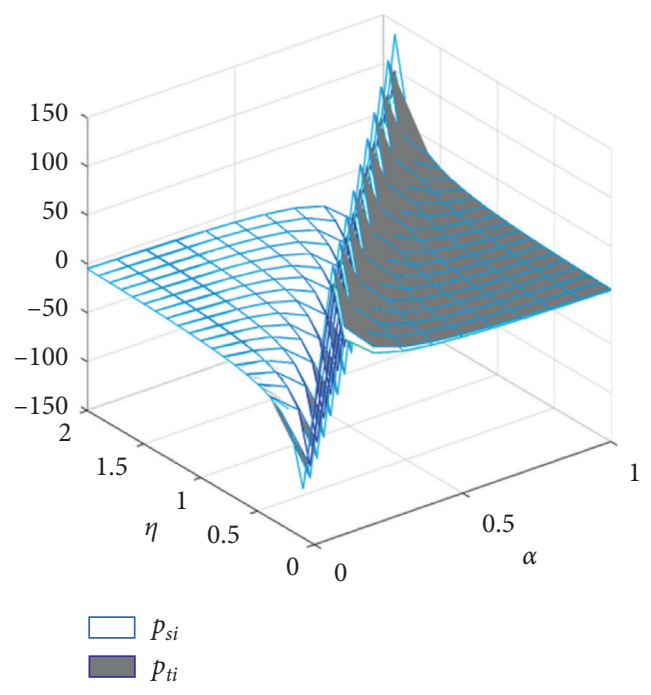

(a)

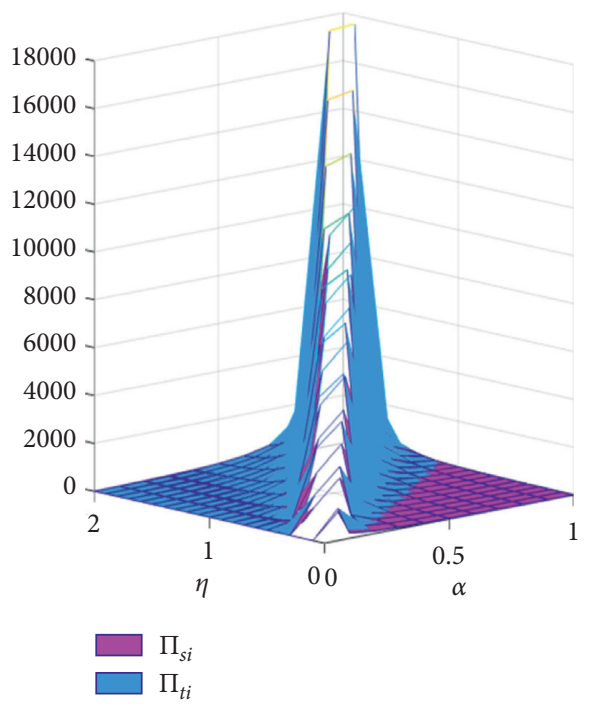

(b)

Figure 8: Price strategies and profits comparison. (a) $p_{s i}$ and $p_{t i}$. (b) $\Pi_{s i}$ and $\Pi_{t i}$.

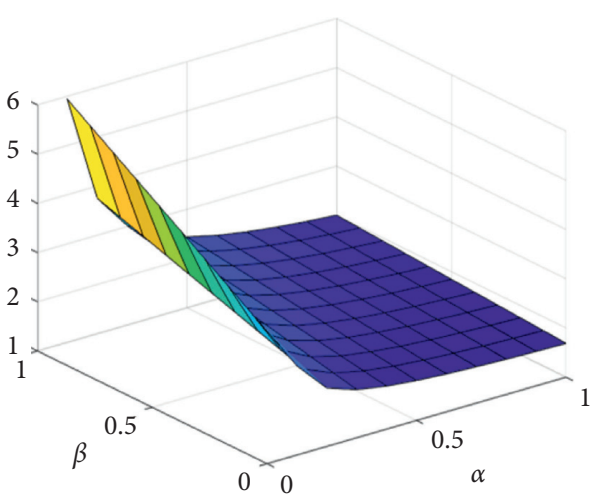

(a)

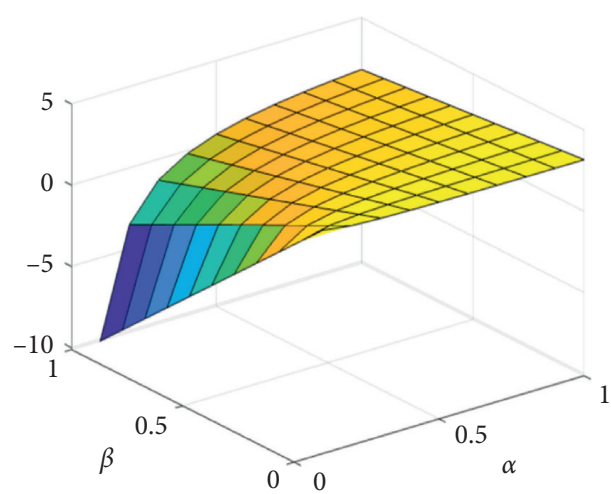

(b)

FIgURE 9: Price strategies under the Stackelberg game. (a) $p^{L}$ (b) $p^{F}$.

the previous paper, we analyzed two decision sequences of two e-commerce firms in the Stackelberg game. One is that the leading firm chooses SDL, and the follower chooses TPL. The other is that the leading firm chooses the TPL, and the follower firm chooses SDL. If the leader chooses the e-commerce platform SDL mode, the follower will choose the TPL mode. We can see from Figure 9 that the behavior of consumers has a great impact on the decision-making of firms. Figure 9(a) shows that when the leading firm chooses SDL, with the increase of consumer price sensitivity, the price strategy of firm presents a downward trend. At the same time, when other parameters remain unchanged, with the increase of consumer service sensitivity, consumers pay less attention to price changes, and firms can slightly increase their prices. Figure 9(b) represents the price decision of the following firm. The follower tends to react according to the decisions of the leaders. In the figure, prices of firms follow the trend of growth, because when the leading firm reduces prices, to ensure the balance of the market, the following firm will increase its prices accordingly. By comparing the price strategies of the two firms, we find that the price set by the leader is higher than that of the follower at the beginning, and then with the increase of consumer price sensitivity, the price of the leader will gradually be lower than that of the follower. Consumer demand is showing the same trend.

Figures 10(a) and 10(b) show the price strategies and profits comparison. Similarly, we have compared the profits of the two firms, and it is obvious that the follower who chooses the TPL mode benefits much more than the leader who chooses the SDL mode. Although the leader of the firms occupies the priority to choose, the follower firm can make the best response according to the leader's decision. Showing the advantage of late mover. In addition, the choice of TPL mode to a certain extent occupies the price advantage, which can attract more consumers. If the leader chooses the TPL 


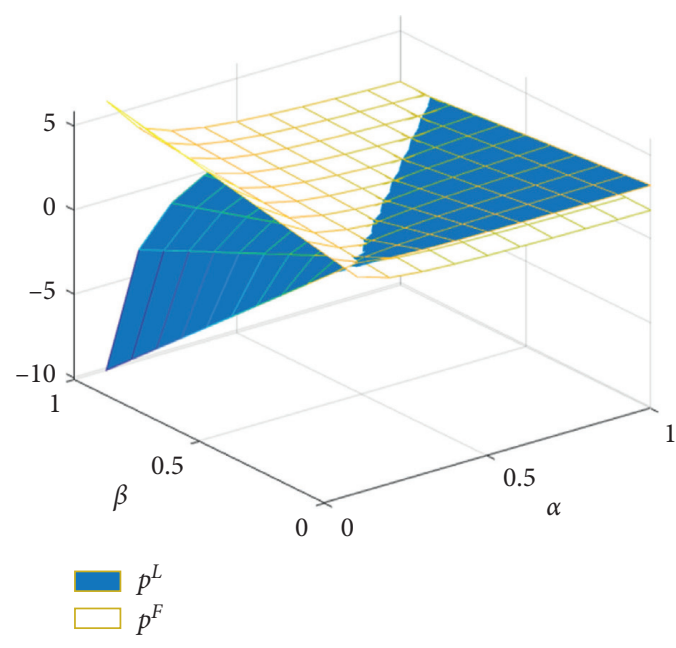

(a)

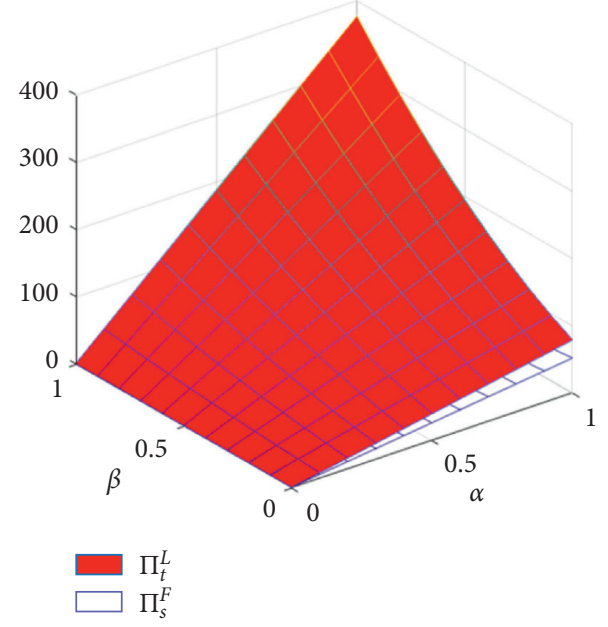

(b)

Figure 10: Price strategies and profits comparison. (a) $p^{L}$ and $p^{F}$ (b) $\Pi_{t}^{L}$ and $\Pi_{s}^{F}$.

mode, the follower will choose the e-commerce platform SDL mode. When the leading firm chooses the TPL mode, and the follower firm chooses the SDL mode, we also make a comparative analysis of price strategies and profit. As can be seen from Figure 10, when the leading firm chooses the TPL, and the follower firm chooses the SDL, their price strategies and benefits are exactly interchangeable with the former decision-making situation. The price setting of the leading firm presents an upward trend with the increase of consumer price sensitivity, and the corresponding follower firm presents a downward trend. The earnings of the leader grow faster than those of the follower. By comprehensively comparing the two different logistics strategies of two competitive e-commerce firms in the context of the Stackelberg game, we can find that no matter what the decision-making order is, firms that choose the TPL mode tend to have higher profits. In addition, the decision-making of e-commerce firms is affected by the factors of consumer behavior, which plays a decisive role in the market demand.

\section{Conclusions}

This paper considers the pricing and logistics policies in competitive e-commerce firms. There are two logistics distribution modes with service competition: the e-commerce platform self-distribution mode and third-party logistics mode. When determining their pricing and logistics strategies, e-commerce firms need to consider not only the behavioral factors of consumers, but also the competitiveness among firms. Motivated by previous literature that seldom used models to study logistics selection, and the factors considered are relatively simple, we develop a model with consumer behavior under the simultaneous decision situation and Stackelberg game. We analyze the pricing and logistics strategies change trend of e-commerce firms under different decision-making situations and find out the optimal strategy for e-commerce firms. First, we consider the price game between two firms in the simultaneous decision situation. We analyze the price strategy and revenue change of two firms when they choose the same logistics mode. Then, under the Stackelberg game, we consider the price sensitivity and service sensitivity of consumers to establish the consumer utility model. Based on the utility model, we get the consumer demand function. Finally, we propose numerical analysis to identify our models. Based on our research, some main conclusions are obtained as follows:

(1) Consumer behavior factors have a great impact on the decision-making of e-commerce firms; not only that, but the competitiveness between e-commerce firms also has an impact on their decision-making.

(2) Under different decision-making situations, the price strategies of e-commerce firms are different, and the game right relationship among channel members has great influence on decision-making.

(3) In general, no matter what decision-making situation the two firms are in, the TPL mode makes e-commerce firms more convenient and profitable. This is consistent with the fact that a large number of firms choose logistics outsourcing in real life.

There are some limitations in this paper. Firstly, more factors can be considered in the choice of logistics mode and pricing strategies among competitive e-commerce firms. Secondly, we only consider the sensitivity of the consumer and ignore other characteristics of the customer. Thirdly, a large amount of actual data is needed to further verify the completeness and applicability of the conclusion. Therefore, further research can be done based on this paper.

\section{Data Availability}

No data were used in this study.

\section{Conflicts of Interest}

The authors declare that they have no conflicts of interest. 


\section{Acknowledgments}

This paper was supported by the Shanghai Philosophy Social Science Project (2020BGL010).

\section{References}

[1] J. Shu and J. Sun, "Designing the distribution network for an integrated supply chain," Journal of Industrial and Management Optimization, vol. 2, no. 3, pp. 339-349, 2006.

[2] A. E. Ellinger, D. F. Lynch, J. K. Andzulis, and R. J. Smith, "BTo-B E-commerce: a content analytical assessment of motor carrier websites," Journal of Business Logistics, vol. 24, no. 1, pp. 199-220, 2011.

[3] Y. Yu, X. Wang, R. Y. Zhong, and G. Q. Huang, "E-commerce logistics in supply chain management: practice perspective," Procedia CIRP, vol. 52, pp. 179-185, 2016.

[4] H. Lee and S. Whang, "Winning the last mile of E-commerce," Mit Sloan Management Review, vol. 42, no. 4, pp. 54-62, 2001.

[5] F. Chen, L. Yong, Y. Xue et al., "Online and offline cooperation under buy-online, pick-up-in-store: pricing and inventory decisions," Journal of Industrial and Management Optimization, vol. 15, no. 3, pp. 1455-1472, 2019.

[6] Y. Wang and D. Sang, Multi-Agent Framework for Third Party Logistics in E-Commerce, Pergamon Press, vol. 29, no. 2, , pp. 431-436, Elmsford, NY, USA, 2005.

[7] V. Choudhary, A. Ghose, T. Mukhopadhyay, and U. Rajan, "Personalized pricing and quality differentiation," Management Science, vol. 51, no. 7, pp. 1120-1130, 2005.

[8] H. Robert, "The value chain and e-business in exporting: case studies from Ghana's non-traditional export (NTE) sector," Telematics and Informatics, vol. 27, no. 3, pp. 323-340, 2010.

[9] S. Qu, H. Yang, and Y. Ji, "Low-carbon supply chain optimization considering warranty period and carbon emission reduction level under cap-and-trade regulation," Environment, Development and Sustainability, 2021.

[10] T. Peral, B. Ecem, T. Seyhan, and A. Mustafa, "The impact of barriers and benefits of e-procurement on its adoption decision: an empirical analysis," International Journal of Production Economics, vol. 158, pp. 77-90, 2014.

[11] N. Hong-Oanh, "Critical factors in e-business adoption: evidence from Australian transport and logistics companies," International Journal of Production Economics, vol. 146, no. 1, pp. 300-312, 2013.

[12] C. Mu, J. Pei, and H. Yu, "An effective pricing model for the congestion alleviation of e-commerce logistics," Computers and Industrial Engineering, vol. 129, pp. 368-376, 2019.

[13] D. Chen, J. Ignatius, D. Sun et al., "Reverse logistics pricing strategy for a green supply chain: a view of customers' environmental awareness," International Journal of Production Economics, vol. 3, pp. 366-385, 2018.

[14] Z. Chu, B. Feng, and F. Lai, "Logistics service innovation by third party logistics providers in China: aligning guanxi and organizational structure," Transportation Research Part E: Logistics and Transportation Review, vol. 118, pp. 291-307, 2018.

[15] G. Veena and P. Gopinath, "Optimal information policy in discrete-time queues with strategic customers," Journal of Industrial and Management Optimization, vol. 15, no. 2, pp. 689-703, 2019.

[16] W. Tong, D. Mu, F. Zhao, G. P. Mendis, and J. W. Sutherland, "The impact of cap-and-trade mechanism and consumers' environmental preferences on a retailer-led supply Chain,"
Resources, Conservation and Recycling, vol. 142, pp. 88-100, 2019.

[17] S. Qu, Y. Li, and Y. Ji, "The mixed integer robust maximum expert consensus models for large-scale GDM under uncertainty circumstances," Applied Soft Computing Journal, vol. 107, Article ID 107369, 2021.

[18] H. K. Shin, A. Kim, and C. W. Lee, "Relationship between consumer's preference and service attributes in mobile telecommunication service," Expert Systems with Applications, vol. 38, no. 4, pp. 3522-3527, 2011.

[19] J. Cai, X. Hu, P. R. Tadikamalla, and J. Shang, "Flexible contract design for VMI supply chain with service-sensitive demand: revenue-sharing and supplier subsidy," European Journal of Operational Research, vol. 261, no. 1, pp. 143-153, 2017.

[20] L. Zheng, C. Xu, and K. Ming, "The effect of customer value and power structure on retail supply chain product choice and pricing decisions," Omega, vol. 77, pp. 115-126, 2018.

[21] X. Hu and P. Su, "The Newsvendor's Joint Procurement and pricing problem under price-sensitive stochastic demand and purchase price uncertainty," Omega, vol. 79, pp. 81-90, 2018.

[22] K. Kogan and F. El Ouardighi, "Autonomous and include production learning under price and quality competition," Applied Mathematical Modelling, vol. 67, pp. 74-84, 2018.

[23] G. Hua, S. Wang, and T. C. E. Cheng, "Price and lead time decisions in dual-channel supply chains," European Journal of Operational Research, vol. 205, no. 1, pp. 113-126, 2010.

[24] A. E. E. Eltoukhy, Z. X. Wang, F. T. S. Chan, and X. Fu, "Data analytics in managing aircraft routing and maintenance staffing with price competition by a Stackelberg-Nash game model," Transportation Research Part E: Logistics and Transportation Review, vol. 122, no. C, pp. 143-168, 2019.

[25] S. Qu, G. Jiang, Y. Ji et al., "Newsvendor's optimal decisions under stochastic demand and cap-and-trade regulation," Environment, Development and Sustainability, 2021.

[26] L. Feng, K. Govindan, and C. Li, "Strategic planning: design and coordination for dual-recycling channel reverse supply chain considering consumer behavior," European Journal of Operational Research, vol. 260, no. 2, pp. 601-612, 2017. 